\title{
Attitude of Indian Youth towards Homosexuality
}

\author{
Sahni S. ${ }^{1}$, Gupta B. ${ }^{2}$, Nodiyal K. ${ }^{3}$, Pant V. ${ }^{4}$
}

\section{ABSTRACT}

Homosexualism is behaviour or a phenomenon in which individuals of the same sex are attracted to or have sexual relations with each other. In India, homosexuality is a taboo subject. Much research has not been conducted to understand the attitude of Indian youth towards homosexuality. The aim of the present research was to measure the implicit attitude, and a comparative analysis between the contact group (those who are in contact with homosexual individuals) and the non-contact group (those who neither know nor are in touch with homosexual individuals) was conducted. Implicit Association Test (Greenwald, McGhee, Schwartz, 1998) was used to gauge the implicit attitude towards homosexual individuals. 100 (50 males and 50 females) undergraduate and graduate students of Delhi and NCR were taken as sample in the study. It has been highlighted through various studies that people might show a positive or a neutral attitude towards homosexuality but unconsciously it may not always be the case. The contact hypothesis (Allport, 1954) suggests that the prejudice against homosexuals can be mitigated by encouraging interpersonal contact between non-homosexual and homosexual population. The findings of this study suggests that the contact group held a positive attitude towards homosexuals ( 30 out of 50), while the non-contact group held a negative one (40 out of $50)$.

Keywords: Contact hypothesis, Homosexuality, Implicit attitude, Implicit association test (IAT), Indian youth

Homosexuality is a phenomenon that has been prevalent since time immemorial. However in the recent era, its prevalence and awareness has seen a quantum jump. Homosexualism is behaviour or a phenomenon in which individuals of the same sex are attracted to, or have sexual relations with each other. Homosexuality is a taboo subject in India, throughout the upbringing an individual is unknowingly taught that it is an unnatural phenomenon, which leads to homonegativity (Lottes \& Grollman, 2010; Wrench, 2005): the intellectual disapproval of

\footnotetext{
${ }^{1}$ Students of Department of Applied Psychology, Vivekananda College, University of Delhi, Delhi, India

${ }^{2}$ Students of Department of Applied Psychology, Vivekananda College, University of Delhi, Delhi, India

${ }^{3}$ Students of Department of Applied Psychology, Vivekananda College, University of Delhi, Delhi, India

${ }^{4}$ Students of Department of Applied Psychology, Vivekananda College, University of Delhi, Delhi, India *Responding Author

(C) 2016 Sahni S, Gupta B, Nodiyal K, Pant V; licensee IJIP. This is an Open Access Research distributed under the terms of the Creative Commons Attribution License (http://creativecommons.org/licenses/by/2.0), which permits unrestricted use, distribution, and reproduction in any Medium, provided the original work is properly cited.
} 


\section{Attitude of Indian Youth towards Homosexuality}

homosexuals. We perceive ourselves to be living in times of heightened self- awareness and yet when certain individuals of the society conform to their non-heterosexual orientation, we tend to socially exclude them.

An attitude can be defined as an enduring organization of motivational, emotional, perceptual and cognitive processes with respect to some aspect of the individual's world.

In the present research we are measuring the implicit attitude of Indian youth towards homosexuality. An implicit attitude is an automatic and unconscious response to the attitude object whereas an explicit attitude is conscious (Timothy D. Wilson, 2000). Thus, implicit attitude is measured because people tend to hold on to their prejudices, all the while, appearing to have overcome them to become socially desirable. Prejudice is a prejudgement of a group and its individual members (Myers, 2012). It is a social phenomenon involving depersonalization; in this case, group based negative affect effects our attitude towards homosexual individuals as we see them as representatives of the target group, i.e., the homosexual community.

To measure the implicit attitude we used Implicit Association Test (Greenwald, McGhee \& Shwartz, 1998), which aims at tapping into a person's implicit mental attitudes towards a certain concept or issue. We used the sexuality (gay-straight) IAT which shows biases towards gays that are not endorsed and may even be contradictory to what one consciously believes about homosexuality.

Homosexuality has its historical base in India; it has been extensively explained in Rigveda. The carvings and depictions in the famous temples of Khujarao,Konark and Puriare proof of the same. India is also the birthplace of Vatsanaya's Kamasutra that includes a complete chapter referring to homosexuality (Chapter IX; Auparistaka). Thus Hinduism has always been open to various ideas of sexuality in the ancient as well as medieval times. However, most other dominant religions are known to discourage homosexuality. Christianity considers homosexuality a sin. The Bible (Leviticus 18:22; Leviticus 20:13) lays down death penalty for ones who engage in such activities. Islam is also against homosexuality. The Quran (Quran 7:8084; Quran 26:165-166) considers homosexuality as sinful and unnatural. It believes such behaviours should not be desired by men and does not even acknowledge lesbianism.

Nature and nurture also play a role in defining one's sexuality. It has been argued whether homosexuality is a result of nature or nurture. Several studies have been conducted to resolve the nature- nurture debate. Various researchers (David Halperin \& Jean Foucault, 1995; Earnest Kaullman, 1951; J Michael Bailey \& Richard Pillard, 1990; Simon Levay, 1991) have conducted studies in support of the nurture argument, while several others (D.F. Swab, 1990; Karen Hooker, 1957; Laura S. Allen, 1992) have tried to prove the nature argument. Based on these studies, it was concluded that both nature and nurture play an important role in determining an individual's sexual orientation. (Johnson, 2003) 


\section{Attitude of Indian Youth towards Homosexuality}

According to the psychodynamic perspective, humans are born with unfocussed sexual libidinal drives and are innately bisexuals. They become homosexual or heterosexual as a result of their experience with parents and others (Freud, 1905) whereas Ellis (1901) argued that homosexuality is inborn and therefore not immoral and not a disease. However, the American Psychological Association (APA) categorized it as a disease under Diagnostic and Statistical Manual (DSM) until the year 1952. Taking into consideration the finding of Hooker's (1957) study, it was removed from the list of mental disorders under DSM in 1973.

The stigma associated with homosexuality is still prevalent and the legal picture of various countries, including India, continues to consider it abnormal and hence a crime. Under section 377 of Indian Penal Code (IPC) (1860) homosexual intercourse was considered a criminal offense till 2009. But on 23 February 2012, the Supreme Court of India reintroduced the law. Currently the battle to decriminalize it is still on-going. In the Western context, several studies on attitude towards homosexuality have already been conducted and found that few factors that influence attitude towards homosexuality are gender, age and education level. Numerous studies examining gender of respondent differences have shown that men generally have more negative attitudes towards homosexuality than do women (Black et al 1998; Finlay and Walther 2003; Hayes 1997; Herek 1988). Most of the research conducted with adult samples suggests that older people are more prejudiced towards gay men and lesbians than are younger people (Haeberle 1999; Herek and Glunt 1993; Kelley 2001; Lewis 2003) And, in general, 'education' increases acceptance of homosexuality, that is, attitudes improve as a function of time spent in education (Eliason 1995; Herek and Capitanio 1996; Kelley 2001; Kurdek 1988; Lottes and Kuriloff1994; Seltzer 1992; Spark Jones 2000; contra Van de Ven 1994).

Although data from national surveys reveal that attitudes among heterosexuals concerning homosexuality and perceptions of lesbians and gay men have become less disparaging and more tolerant in recent years (Dasgupta \& Rivera, 2006), evidence of criminal enactments of prejudice toward sexual minorities continues to be prevalent in society (Harlow, 2005). A recent study of adults living in the United States in 2005 found that approximately $20 \%$ of the U.S. sexual minority population reported having experienced a crime against their person or as a consequence of their sexual orientation since age 18 (Herek, 2008). Harassment was found to be considerably more widespread, with about one half of sexual minority adults reporting verbal abuse at some time in their adult life. Research over the past two decades suggests that the real cost of sexual orientation prejudice in our society is becoming more apparent, with gay, lesbian, and bisexual adolescents and young adults struggling with serious emotional and psychological consequences of social disapprobation and isolation. In addition to higher than average rates of suicide ideation (Garofalo, Wolf, Wissow, Wood \& Goodman 1999), these young people also experience a greater incidence of substance abuse, sexual abuse, homelessness, parental rejection, emotional isolation, school drop-out. Lipkin (1999) stated that "societal ignorance and fear still restrict appropriate responses to the urgent needs of homosexual youth and adults". The 


\section{Attitude of Indian Youth towards Homosexuality}

absence of the civil rights for sexual minorities, fostered by the federal government, cultivates all manners of discrimination, thereby authorizing the debasement of sexual minorities in the form of verbal and physical abuse perpetuated by children and adults alike (Human Rights Campaign, 2012).

In Indian cultural context, are search was conducted on medical students. The results indicated that the medical students and interns had inadequate knowledge about homosexuality, although they endorsed a neutral stance insofar as their attitude towards homosexuals is concerned (G. Banwari, K. Mistry, A.Soni, N. Parikh \& H. Gandhi, 2004). Crimes against homosexuals are also prevalent in India. According to statistics with the Crisis Interventions Team of LGBT Collective in Telangana, there have been 15 instances of 'Corrective Rapes'. A Corrective rape is a hate crime in which people are raped because of their perceived sexual orientation or gender identity. The common intended consequence of the rape, as seen by the perpetrator, is to turn the person heterosexual or to enforce conformity with gender stereo types. In Bollywood culture as well, gay men and lesbians are included in the movies as comic reliefs, for instance, Dostana, 2008; Partner, 2007; Student of the Year, 2012. Meanwhile, movies depicting homosexuality in its true essence have either been banned (for example, Fire, 1996) or been given an "A" certificate by the censor board of India (for example, Aligarh, 2016).

Enhancing knowledge of Indian youth by incorporation of homosexuality related issues in the society could help reduce prejudice towards the sexual minority in our country.

\section{Rationale}

The study has been conducted with the purpose of exploring the deeply ingrained prejudices against homosexuals in India. From previous researches done by some present day researchers, it has been observed that explicitly people tend to display a neutral or even a positive attitude towards homosexuals while a negative attitude is held at an implicit level. Attitude researchers, therefore, are increasingly relying on implicit assessment of attitudes. Since not much research has been conducted in the Indian context using the Implicit Association Test (IAT), the present study makes use of this test.

To validate contact hypothesis (Allport, 1954)as an effective tool of reducing prejudice, comparative analysis of contact and non-contact group was done.

\section{Objective}

i. To explore the implicit attitude of the Indian youth towards homosexuality.

ii. To study the difference of attitude in contact group (those who are in contact with homosexual individuals) and the non-contact group (those who neither know nor are in touch with homosexual individuals). 


\section{Attitude of Indian Youth towards Homosexuality}

\section{METHOD}

\section{Sample}

The sample comprised of 100 undergraduate and graduate students, 50 in the contact group and 50 in the non-contact group (25 females and 25 males in each).

The participants were chosen through purposive sampling (snowball sampling). The participants were in the age group of 18-25 years residing in Delhi and NCR from the middle SES and well versed with English language and handling of a computer keyboard.

\section{Measures}

The Implicit Association Test (https://implicit.havard.edu/implicit/) was used. It measures the strength associations between concepts and evaluations or stereotypes. The main idea is that making a response is easier when closely related items share the same response key. The internal consistency value of the IAT as measured by researchers ranged from 0.7 to 0.9 . In terms of test retest reliability also the IAT is considered to be a stable measure.

\section{Procedure}

Implicit Association Test (IAT) was conducted on the participants. The online version of the test was administered (https://implicit.havard.edu/implicit/).A sample was selected through snowball sampling, i.e., the participants were approached through a chain of friends.

Confidentiality of the participants was maintained and they were assured that their identities would not be revealed.

\section{Ethical Considerations of the Study}

1. Informed written consent was taken from all participants.

2. Confidentiality issues were clarified. All participants were assured that their identities would not be revealed.

3. The participants were briefed about the test. Further questions by participants related to the Implicit Association Test were also answered.

\section{RESULT}

The objective of our study was to assess the implicit attitude of Indian youth towards homosexuality. 60 out of 100 participants showed an automatic preference for straight people as compared to gay people (Table 2).

In the comparative analysis conducted between the contact and the non- contact group, a difference between attitudes of the two groups was found. Chi square test was used; the value obtained is shown in table 3 given below. 


\section{Attitude of Indian Youth towards Homosexuality}

\section{FINDINGS AND ANALYSIS}

Table 1: Numerical Codes used to tabulate the data

\begin{tabular}{|l|l|}
\hline \multicolumn{1}{|c|}{ Numerical Code } & \multicolumn{1}{|c|}{ Interpretation } \\
\hline+3 & \begin{tabular}{l} 
Strong automatic preference towards Gay People as compared to Straight \\
People. \\
\hline+2
\end{tabular} \\
\hline+1 & $\begin{array}{l}\text { Moderate automatic preference towards Gay People as compared to } \\
\text { Straight People. }\end{array}$ \\
\hline 0 & $\begin{array}{l}\text { Slight automatic preference towards Gay People as compared to Straight } \\
\text { People. }\end{array}$ \\
\hline-1 & $\begin{array}{l}\text { No automatic preference between Straight People and Gay People. } \\
\text { People. }\end{array}$ \\
\hline-2 & $\begin{array}{l}\text { Moderate automatic preference towards Straight People as compared to } \\
\text { Gay People. }\end{array}$ \\
\hline-3 & $\begin{array}{l}\text { Strong automatic preference towards Straight People as compared to Gay } \\
\text { People. }\end{array}$ \\
\hline
\end{tabular}

Table 2: Data Table For Contact and Non-contact Groups

\begin{tabular}{|l|l|l|l|l|}
\hline S. No. & Contact Group & \multicolumn{3}{l|}{ Non-Contact Group } \\
\hline & Male & Female & Male & Female \\
\hline 1. & +2 & +3 & -3 & -1 \\
\hline 2. & +2 & +3 & -2 & -1 \\
\hline 3. & +1 & +3 & 0 & -1 \\
\hline 4. & +1 & 0 & -3 & -1 \\
\hline 5. & 0 & +1 & -3 & +2 \\
\hline 6. & +2 & -3 & -1 & -2 \\
\hline 7. & -3 & -1 & -2 & -2 \\
\hline 8. & -1 & +1 & +2 & -2 \\
\hline 9. & -2 & +2 & -3 & -3 \\
\hline 10. & 0 & -1 & -1 & +1 \\
\hline 11. & +1 & +2 & -1 & +3 \\
\hline 12. & +2 & -1 & -2 & +1 \\
\hline 13. & +3 & +3 & -1 & -2 \\
\hline 14. & +2 & -1 & -3 & 0 \\
\hline 15. & +1 & +2 & -2 & -1 \\
\hline 16. & +2 & -3 & -1 & -2 \\
\hline 17. & -3 & -1 & -2 & -2 \\
\hline 18. & -1 & +1 & +2 & -2 \\
\hline 19. & -2 & +2 & -3 & -3 \\
\hline
\end{tabular}

(c) The International Journal of Indian Psychology, ISSN 2348-5396 (e)| ISSN: 2349-3429 (p) | 64 
Attitude of Indian Youth towards Homosexuality

\begin{tabular}{|c|c|c|c|c|}
\hline \multirow[t]{2}{*}{ S. No. } & \multicolumn{2}{|c|}{ Contact Group } & \multicolumn{2}{|c|}{ Non-Contact Group } \\
\hline & Male & Female & Male & Female \\
\hline 20. & 0 & -1 & -1 & +1 \\
\hline 21. & +1 & +2 & -1 & +3 \\
\hline 22. & +2 & -1 & -2 & +1 \\
\hline 23. & +3 & +3 & -1 & -2 \\
\hline 24. & +2 & -1 & -3 & 0 \\
\hline 25. & +1 & +2 & -2 & +1 \\
\hline
\end{tabular}

Table 3: Table showing chi square values

\begin{tabular}{|l|l|l|l|}
\hline & Positive Responses & Negative Responses & Marginal Row Totals \\
\hline Contact Group & 30 & 20 & 50 \\
\hline Non-contact Group & 10 & 40 & 50 \\
\hline $\begin{array}{l}\text { Marginal Column } \\
\text { Totals }\end{array}$ & 40 & 60 & $\mathrm{~N}=100$ \\
\hline$x^{2}$ & & & $16.667^{* *}$ \\
\hline
\end{tabular}

${ }^{* *} \mathrm{p}<0.5$, the $\mathrm{p}$ value is 0.000045

\section{DISCUSSION}

Homosexuality (from Ancient Greek ómós, meaning "same", and Latin sexus, meaning "sex") is romantic attraction, sexual attraction or sexual behaviour between members of the same sex or gender. As a sexual orientation, homosexuality is "an enduring pattern of emotional, romantic, and/or sexual attractions" to people of the same sex. It "also refers to a person's sense of identity based on those attractions, related behaviours, and membership in a community of others who share those attractions."

The term homosexuality in itself triggers the images of people protesting, pride parades, pink pages, people holding placards asking for equal rights, in our minds.

The objective of our study was to measure the implicit attitude of Indian youth towards Homosexuality using the Implicit Association Test (IAT). The differences in implicit attitudes of contact group (those in contact with homosexual individual) and non-contact group (those who neither know and are nor in touch with homosexual individuals) were also analyzed.

Jung (1992) defined attitudes as a readiness of the anima to act in an assertive way. Attitudes are dual in nature (Wilson et.al, 2000), one attitude being implicit (i.e. unconscious) and the other being explicit (i.e. unconscious). To measure the implicit attitude Implicit Association test was used, as mentioned above. It measures the strength of associations between concepts and 


\section{Attitude of Indian Youth towards Homosexuality}

evaluations (e.g. good or bad) or stereotypes. For the present study the sexuality (gay-straight) IAT was used.

Incongruence between explicit and implicit attitudes leads to prejudice (aversive prejudice). Prejudice is an unverified prejudgment about a group, which, in most cases is negative.

In the present study, the Implicit Association Test was conducted on a sample of 100 graduate and undergraduate students categorized into contact group (50; 25 males and 25 females) and non-contact group(50; 25 males and 25 females).

The findings suggest that out of the 100 participants considered, 60 were found to have held an automatic preference for straight people as compared to gay people, as shown in table 2 . Thus, the general trend depicts that people tend to have a negative implicit attitude towards homosexuals. This can be explained in the light of certain socio-cultural norms which exclude the homosexual community from the larger society. This has a very noticeable effect on implicit attitude of the population. This can be supported by various studies. Livingston et al. (2002) examined the effect of mainstream culture on one's implicit attitude towards their social group. Implicitly, one will follow the cultural attitudes towards their social group that they perceive from mainstream culture in their society, whether they are positive or negative.

Olson and Fazio et al. (2004) have suggested that at an implicit level one's personal attitude can be influenced by the social or cultural norms that one perceives. Furthermore, this may be due to a weak distinction between one's personal attitude and extra-personal associations (e.g., one's cultural evaluations) towards an attitude object at the implicit level. From this we can conclude that implicit attitudes are indeed reflective of experiences but can also be shaped by the cultural context.

Table 2 also shows that more participants from the non-contact group, i.e., 30 out of the 50 participants, while, a lesser number of participants from the contact group, i.e., 20 out of 50 participants, had a negative implicit attitude towards gay people. However, 30 out of 50 individuals in the contact group held a positive implicit attitude, whereas, only 10 individuals from the non-contact group held a positive implicit attitude towards homosexuals. This difference obtained is the consequence of the contact hypothesis adopted in the present study. Contact hypothesis (Allport, 1954) states that under appropriate conditions, interpersonal contact is one of the most effective ways to reduce prejudice between minority and majority group members. This can be supported by the study done by Rudman and Goodwin (2004), who found that individuals primarily raised by mothers showed more positive implicit attitude towards women than men. It has also proven to be highly effective in alleviating prejudice directed towards homosexuals. Supporting this, Herek (1987) in his study found that college students who had pleasant interactions with a homosexual tend to generalize from that experience and accept homosexuals as a group. Another study done by Herek \& Capitanio (1996) found that contact 


\section{Attitude of Indian Youth towards Homosexuality}

experiences with two or three homosexuals are associated with more favourable attitudes than are contact experiences with one.

It was also observed that in the non-contact group, males showed a more negative implicit attitude towards homosexuals than their female counterparts. This is evident from table 2 showing 23 negative responses from males while 17 from females. Out of these, for males, 7 showed strong automatic preference for straight people as compared to gay people, whereas, the females of the same group only had 2 such responses. On the other hand, females from the noncontact group $(n=25)$ include 2 responses indicating a strong automatic preference for gay people as compared to straight people, while no such responses were found in the males' data. This can be attributed to the culturally ingrained beliefs about masculinity and femininity. Specifically, gender socialization teaches men and women what society believes are the behaviours appropriate for their corresponding biological sex, so that the individual learns to devalue and dislike, and therefore avoid, any behaviour that could be constructed as counter to particular gender roles, including homosexuality, in order to be accepted by the society (Whitley, 2001). Studies suggest that heterosexual men whose identity is closely tied to their masculinity and who try to live up to a standard of extreme masculinity have more negative attitudes toward gay men. Social identity theory (Tajfel \& Turner, 1979) too suggests that expressions of homonegativity are sometimes used by heterosexual men to protect threats to their heterosexual identity (Hamner, 1992). Since heterosexual men have a vested interest in maintaining their sense of masculinity, both due to the privileges it provides and the stigma associated with failing to do so, hence, the theory would suggest that both gay men and lesbians pose a threat to traditional homogenic masculinity.

Chi square was used to find out significant difference between frequencies of negative and positive responses gathered from the contact and non-contact group. The value calculated was 16.667. At $\mathrm{p}<0.05$, this obtained value is significant. The test is appropriate in our research since the sample size taken was small.

\section{LIMITATIONS AND FUTURE DIRECTIONS}

1. The sample size was small.

2. The sample considered was confined to the Delhi-NCR area.

3. The contact hypothesis can sometimes produce unfavourable results, desegregating the individual from the group as contact increases, leading to stronger prejudices.

We are planning to carry this research further and explore the gender differences that maybe found in the implicit attitude of males and females with respect to homosexuality.

\section{CONCLUSIONS}

This study highlights that the implicit attitude of majority of the participants (60 out of 100) was negative towards gay people.

(C) The International Journal of Indian Psychology, ISSN 2348-5396 (e)| ISSN: 2349-3429 (p) | 67 


\section{Attitude of Indian Youth towards Homosexuality}

A comparative analysis conducted between the contact and the non-contact group reveals a difference between attitudes of the two groups. The chi square test was used to statistically understand whether the difference was significant or not. The value obtained (16.667) turned out to be significant at $\mathrm{p}<0.05$. Thus, it was found that individuals in contact with homosexuals had a more positive implicit attitude towards homosexuals than people who were not in contact.

\section{Acknowledgments}

The author appreciates all those who participated in the study and helped to facilitate the research process.

\section{Conflict of Interests}

The author declared no conflict of interests.

\section{REFERENCES}

A. G. Greenwald, D. E. (1998). Measuring individual differences in implicit cognition: The implicit association test. JPSP, 74, 1464-1480.

Allport, G. (1954). The Nature of Prejudice. Addison-Wesley .

Banwari G, M. K. (2015). Medical students and interns' knowledge about and attitude towards homosexuality. . J Postgrad Med ;61, 95-100.

Capitanio, G. M. (1996). “Some of My Best Friends”:Intergroup Contact, Concealable Stigma, and Heterosexuals' Attitudes Toward Gay Men and Lesbians. Personality and Social Psychology Bulletin, 412-424.

Fairchild, M., \& Huda. (2014, November 29). About.com. Retrieved from about religion.

Freud, S. 1. (1960). Three essays on the theory of sexuality. Standard Edition volume7, pp. 123246.

Herek, G. M. (2008). Hate Crimes and Stigma-Related Experiences Among Sexual Minority Adults in the United States. Journal of Interpersonal Violence, 54-74.

Herek, G. M. (2012). Facts about Homosexuality and Mental Health. Retrieved from www.psc.dss.ucdavis.edu: http://psc.dss.ucdavis.edu/rainbow/HTML/facts_mental_health.HTML

Implicit Attitude. (n.d.). Retrieved from Wikipedia: https://en.wikipedia.org/wiki/Implicit_attitude\#Culture_and_social_norms

Jain, R. (2015). Parents use ‘corrective rape' to ‘straight' en their gay kids. Hyderabad: Times of India.

Johnson, R. D. (2003, April). http://allpsych.com/journal/homosexuality/. Retrieved from www.allpsych.com.

Jung. (2012, March 28). Jung's Definitions. Retrieved from Blogger: http://attitude-psychology.blogspot.in/2012/03/jungs-definition.html 


\section{Attitude of Indian Youth towards Homosexuality}

Lottes, I. L. (2010, December). Conceptualization and Assessment of Homonegativity: International Journal of Sexual Health. Retrieved from www.academia.edu: http://dx.doi.org/10.1080/193.176.11.2010.489358

Myers, D. G. (2012). Prejudice. In D. G. Myers, Social Psychology. New York: McGraw-Hill.

Rivera, N. D. (2006). From automatic anti-gay prejudice to behavior: The moderating . Journal of Personality and Social Psychology, 268-280.

Robert Garofalo, R. C. (1999). Sexual Orientation and Risk of Suicide Attempts Among a Representative Sample of Youth . rchives of Pediatrics and Adolescent Medicine 153, 487-493.

Rudman, L. A. (2004). Gender differences in automatic in group bias: Why do women like women more than men like men? Journal of Personality and Social Psychology, 494-509.

Timothy D. Wilson, S. L. (2000). ResearchGate. Retrieved from A Model of Dual Attitudes: Psychlogical Reviews: people.virginia.edu

Turner, T. \&. (2012). Self in Social World. In B. \&. Branscombe, Social Psychology. Pearson . Vatsayayana. (2012). Ancient Indian Philosophy of Kama Sutra on Homosexuality. Retrieved from space and Motion: http://www.spaceandmotion.com/kama-sutra-homosexuality.htm

Whitley, B. E. (2001). Gender-Role Variables and Attitudes Toward Homosexuality. Sex Roles, 691-721.

Wikipedia. (2015). Section 377 of the Indian Penal Code. wikipedia.org.

How to cite this article: Sahni S, Gupta B, Nodiyal K, Pant V (2016), Attitude of Indian Youth towards Homosexuality, International Journal of Indian Psychology, Volume 4, Issue 1, No. 83, ISSN:2348-5396 (e), ISSN:2349-3429 (p), DIP:18.01.168/20160401, ISBN:978-1-365-64761-1 